\title{
Residual formaldehyde after low-temperature steam and formaldehyde sterilization
}

\author{
G. L. GIBSON, H. P. JOHNSTON, AND V. E. TURKINGTON \\ From the Departments of Bacteriology and Biochemistry, Royal Victoria Hospital, Belfast
}

SYNOPSIS The levels of formaldehyde remaining in various articles have been estimated immediately after a low-temperature steam and formaldehyde sterilizing process and after various periods of aeration. These levels have been compared with the levels of ethylene oxide remaining after exposure to an ethylene oxide sterilizing process.

In rubber and polythene and a plastic, formaldehyde levels are low and slowly fall even further. Ethylene oxide levels are relatively much higher even after seven days' aeration.

It is not considered that the residual levels of formaldehyde in rubber, polythene, and a plastic should constitute a danger. Residual levels of formaldehyde in fabrics and paper are higher but this may be of value by giving a self-disinfecting action on storage.

The use of low-temperature steam and formaldehyde for the disinfection and sterilization of heat-labile materials was first put on a practical basis in 1966 by Alder, Brown, and Gillespie working in Bristol. Since then it has been adopted in other centres and has been found to be a useful and acceptable method for processing a wide variety of objects and materials (Gibson and Johnston, 1967).

It is inevitable that any consideration of formaldehyde as a sterilizing agent must take into account its advantages and its disadvantages, particularly in comparison with ethylene oxide, the only practical alternative at this time.

The advantages of formaldehyde lie in its much lower toxicity, its ease of control, and the complete absence of danger from fire and explosion. This allows formaldehyde and steam to be used in a large simple chamber without any special precautions. A disadvantage lies in the need to maintain a temperature of the nature of $80^{\circ} \mathrm{C}$ which may still be damaging to a few objects and materials, although, apart from pacemakers as presently constituted, we know of few objects which can be processed by ethylene oxide which cannot also be processed by low-temperature steam and formaldehyde. Early reports indicated that penetration of narrow-bore tubing was poor (Alder et al, 1966) but a later development has disposed of this problem (Alder, 1968). The new method consists of saturating the chamber with formaldehyde vapour Received for publication 31 January 1968. before the admission of steam by injecting formalin at $2 \mathrm{ml}$ per cubic foot of autoclave space into the chamber after the initial preevacuation stage and reevacuating the vaporized formalin after a minute. This procedure is carried out three times and is then followed by the normal cycle previously detailed (Alder et al, 1966). This modification, however, has not proved to be necessary with our apparatus to penetrate narrow tubing adequately using the cycle we have described (Gibson and Johnston, 1967).

The great practical disadvantage of the toxicity of ethylene oxide really lies in the long 'airing off' period required to ensure that processed articles do not cause poisonous effects when used in tissues or on skin or in contact with fluids entering the body. It has not appeared to us that this type of toxicity should constitute a major problem with formaldehyde and steam sterilization, and indeed preliminary tests (Gibson and Johnston, 1967) appeared to bear this out. However, in view of the importance of freedom from toxicity in articles likely to be associated closely with body fluids for long periods it was decided to investigate this further and to compare in various representative articles the residual levels of formaldehyde after exposure to that process with those of ethylene oxide after exposure to that gas.

Aside from its actual toxic effects, formaldehyde may also be a contact allergen in some people. It has been shown that finishing processes using for- 
maldehyde amine resins applied to textiles may result in allergic contact dermatitis (Marcussen, 1959; Blohm, 1959; Wereide, 1964). The increasing use of the steam and formaldehyde sterilization must therefore raise the question of the risk of such reactions, and must be related to the residual levels of formaldehyde in fabrics treated by this method and comparisons made with 'normal levels' found in paper, cotton, and other textiles finished by formaldehyde amine resins.

\section{MATERIALS AND METHODS}

The apparatus used for formaldehyde and low-temperature steam sterilization is a $21 \mathrm{cu} \mathrm{ft}$ dressings autoclave modified by the manufacturer to provide this additional cycle. A prevacuum with steam pulsing is followed by a steam injection period during which the steam also introduces formaldehyde vapour over four minutes to a total of $180 \mathrm{ml}$ of formaldehyde solution B.P. There is then a sterilizing period of two hours at $80^{\circ} \mathrm{C}$ while a balance is maintained between steam pressure and vacuum, and finally a post-vacuum period, including further steam pulsing, which effectively dries the contents and extracts the formaldehyde.

The ethylene oxide apparatus is a commercial machine with a $0.8 \mathrm{cu} \mathrm{ft}$ chamber. A prevacuum period is followed by exposure to pure ethylene oxide gas (always maintained for safety at subatmospheric pressure) for one hour at $55^{\circ} \mathrm{C}$. A post-vacuum period extracts the ethylene oxide.

Plastic cardiac catheters, polythene tubing, rubber gloves, and rubber catheters were chosen for test exposure to steam and formaldehyde, as they were thought to represent the types of material, though not necessarily the actual articles, which would probably be processed in this way. In addition a few powder sachets were processed and tested to observe the effect on a very absorptive material. Two types of polythene tube, one large-bore and one small-bore, were included. These, together with the rubber gloves and rubber catheter, provided some variation in the surface-area/weight ratio of different articles made of the same materials.

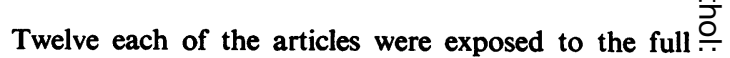
subatmospheric steam and formaldehyde cycle while $\vec{F}$ double wrapped in Kraft paper. Six of each type were $\frac{\rho}{+}$ then immersed within two hours in $250 \mathrm{ml}$ of distilled $\mathrm{O}$ water in a 1 litre conical flask, the flask was sealed, and $\overline{0}$ the contents were agitated and allowed to stand over- $\frac{\text { के }}{2}$ night. The remaining six specimens were allowed to $\overparen{\otimes}$ 'air off' in their paper wraps on the bench at room temperature for 48 hours. They were then immersed in $\%$ distilled water and treated as described above. Two $\vec{\circ}$ samples of each article were not exposed to formaldehyde $\overrightarrow{-}$ and were used as blank controls.

Formaldehyde in the distilled water after overnight $\stackrel{\circ}{\circ}$ extraction was estimated as follows. Duplicate $1.0 \mathrm{ml}$ 용 samples of the water were pipetted into $20 \mathrm{ml}$ test tubes $\mathrm{N}$ and $5.0 \mathrm{ml}$ of chromotropic acid solution was added. The tubes were heated for 15 minutes in a boiling water bath in the absence of excess light. After cooling the purple colour produced was measured spectrophoto- 0 metrically at $580 \mathrm{~m} \mu$.

Standard solutions prepared from Analar formalde- $\overrightarrow{-}$ hyde solution analysed iodometrically were introduced 0 and were treated in the same way as the test solutions. $\overparen{\Phi}$ Distilled water was used in the blank tube.

Chromotropic acid was prepared by dissolving $2 \mathrm{~g}$ of $\underset{\mathbb{D}}{ }$ 1,8 dihydroxy-naphthalene 3,6 disulphonic acid in $200 \mathrm{ml}$ distilled water. Separately $600 \mathrm{ml}$ of concentrated $\mathscr{\odot}$ sulphuric acid was added to $300 \mathrm{ml}$ of distilled water $\infty$ cooled in ice. When cool the diluted sulphuric acid was $\square$ added to the chromotropic acid with mixing.

The mixture should be stored in a brown bottle and prepared freshly every two or three weeks.

\section{RESULTS}

The results of the estimations carried out can be $\frac{O}{3}$ seen in Table I expressed as total formaldehyde $\supsetneq$ extracted from each article and as parts per million of formaldehyde extracted from each article. In each case the results can be seen as estimated immediately after the sterilizing process and after an 'airing off' period of $\mathbf{4 8}$ hours.

These results show that the residual formalde-

TABLE I

FORMALDEHYDE ESTIMATIONS

\begin{tabular}{|c|c|c|c|c|}
\hline Article & $\begin{array}{l}\text { Average } \\
\text { HCHO per } \\
\text { Article }(\mu \mathrm{g})\end{array}$ & $\begin{array}{l}\text { Average } \\
\text { Weight } \\
\text { of Article } \\
\text { (g) }\end{array}$ & $\begin{array}{l}\text { Average } \\
\text { HCHO } \\
(\text { ppm })\end{array}$ & $\begin{array}{l}\text { Unexposed } \\
\text { Control }\end{array}$ \\
\hline $\begin{array}{l}\text { Polythene large bore } \\
\text { Polythene large bore after } 48-\mathrm{hr} \text { airing } \\
\text { Polythene small bore } \\
\text { Polythene small bore after } 48-\mathrm{hr} \text { airing } \\
\text { Rubber gloves } \\
\text { Rubber gloves after } 48-\mathrm{hr} \text { airing } \\
\text { Rubber catheter } \\
\text { Rubber catheter after } 48-\mathrm{hr} \text { airing } \\
\text { Cardiac catheter } \\
\text { Cardiac catheter after } 48-\mathrm{hr} \text { airing } \\
\text { Powder sachet (in } 100 \mathrm{ml} \text { water) } \\
\text { Powder sachet after } 48-\mathrm{hr} \text { airing (in } 100 \mathrm{ml} \\
\text { water) }\end{array}$ & $\begin{array}{r}62.6 \\
41.4 \\
91 \cdot 5 \\
45 \cdot 0 \\
269 \cdot 0 \\
279.4 \\
103.7 \\
65.0 \\
32.0 \\
47 \cdot 0 \\
402.0 \\
393.0\end{array}$ & $\begin{array}{r}6 \cdot 260 \\
6 \cdot 179 \\
5 \cdot 865 \\
6 \cdot 522 \\
12 \cdot 283 \\
12 \cdot 700 \\
12 \cdot 646 \\
13 \cdot 265 \\
4 \cdot 156 \\
4 \cdot 312 \\
1 \cdot 446 \\
1 \cdot 455\end{array}$ & $\begin{array}{r}10.0 \\
6.7 \\
15.6 \\
6.9 \\
21.9 \\
22.0 \\
8.2 \\
4.9 \\
7.7 \\
10.9 \\
278.0 \\
270.0\end{array}$ & $\begin{array}{l}0 \\
0 \\
0 \\
0 \\
0 \\
0 \\
0 \\
0 \\
0 \\
0 \\
0 \\
0\end{array}$ \\
\hline
\end{tabular}
water) 
TABLE II

FORMALDEHYDE ESTIMATION (PPM)

$\mathrm{HCHO}(\mathrm{ppm})$ in Article

\begin{tabular}{|c|c|c|c|c|c|c|}
\hline \multirow[b]{2}{*}{ Article } & \\
\hline & Day 0 & Day 1 & Day 2 & Day 3 & Day 7 & Control \\
\hline Rubber tube large bore & 4.05 & 4.05 & $\mathbf{0}$ & $1 \cdot 35$ & $1 \cdot 35$ & 0 \\
\hline Rubber tube small bore & 1.92 & $7 \cdot 69$ & 0 & 0 & $1 \cdot 92$ & $\mathbf{0}$ \\
\hline Polythene tube & & & & & & \\
\hline large bore & $4 \cdot 86$ & $2 \cdot 08$ & 2.08 & $4 \cdot 17$ & 0.69 & $\mathbf{0}$ \\
\hline Polythene tube & & & & & & \\
\hline $\begin{array}{l}\text { small bore } \\
\text { Cotton cloth }\end{array}$ & $\begin{array}{l}8 \cdot 33 \\
2170 \cdot 0\end{array}$ & $\begin{array}{c}8 \cdot 33 \\
1500 \cdot 0\end{array}$ & $\begin{array}{c}0 \\
433 \cdot 0\end{array}$ & $\begin{array}{r}12 \cdot 5 \\
1060 \cdot 0\end{array}$ & $\begin{array}{c}0 \\
1480 \cdot 0\end{array}$ & $\begin{array}{l}0 \\
4 \cdot 16\end{array}$ \\
\hline Paper & $1470 \cdot 0$ & 1580.0 & $500 \cdot 0$ & 580.0 & $1870 \cdot 0$ & $4 \cdot 44$ \\
\hline Cotton cellular blanket & 270.0 & $214 \cdot 0$ & 92.0 & $158 \cdot 0$ & $114 \cdot 0$ & 0 \\
\hline Woollen blanket & 580.0 & $445 \cdot 0$ & $176 \cdot 0$ & $320 \cdot 0$ & 640.0 & $8 \cdot 0$ \\
\hline
\end{tabular}

hyde is very low in all the articles processed although it reaches higher levels in the powder sachets which were included to represent a particularly absorbent material.

The reduction in formaldehyde levels after 48 hours' aeration is not dramatic at the low levels present but is significant in the case of the smallbore polythene tube at $51 \%(0.005>\mathrm{P}>0.001)$ and the rubber tubing at $40.2 \%(0.01>P>0.005)$.

The low levels obtained would bear out the subjective impression following the formaldehyde process that there is no smell of formaldehyde or other evidence of heavy concentrations of it on rubber and plastic articles. There is, however, a certain tendency for the smell of formaldehyde to cling to fabric and paper.

In order further to investigate the drop in formaldehyde levels over a longer period of aeration, six samples of each of the materials described in Table II were exposed to the process and the levels of formaldehyde after aqueous extraction were estimated as before over seven days' aeration. The results in Table II again show that the levels are very low, and, while there is considerable variation, there is a general downward trend except in cloth and paper. These gave high levels and no evidence of appreciable dispersion within the time of the test.

To provide a comparison of the levels obtained after exposure to formaldehyde and steam with those obtained after exposure to ethylene oxide, similar articles to those in Table II were put through a cycle of sterilization by this method, including one hour's exposure to the gas and post-vacuum dispersal period.

\section{METHOD}

Aqueous extraction was used in the same manner as that described above and the ethylene oxide level determined by conversion to formaldehyde and colometric estimation. The ethylene oxide (at an elevated temperature) is hydrolysed by sulphuric acid to ethylene glycol which in turn is oxidized by periodic acid to yield 2 molecules of formaldehyde. This conversion is quantitative under these conditions (Critchfield and Johnson, 1957).

Of the aqueous extracts, $25.0 \mathrm{ml}$ was pipetted into airtight bottles and $0.5 \mathrm{ml}$ of $0.5 \mathrm{NH}_{2} \mathrm{SO}_{4}$ added to each. The bottles were placed in a water bath at $98^{\circ} \mathrm{C}$ $\pm 2^{\circ} \mathrm{C}$ for 60 minutes. After cooling the contents were transferred with washing by distilled water to a $50-\mathrm{ml}$ stoppered cylinder, $1.0 \mathrm{ml}$ of $0.1 \mathrm{~N}$ sodium periodate was added, mixed, and left for 15 minutes at room temperature. Then $1.0 \mathrm{ml}$ of $5.5 \%$ sodium sulphite was added and the volume made up to $50 \mathrm{ml}$ with distilled water and mixed. Samples of this solution, each of 1.0 $\mathrm{ml}$, were used for the estimation of formaldehyde as described above.

\section{RESULTS}

The levels of residual ethylene oxide as estimated in this way are shown in Table III. They are very considerably higher than the formaldehyde levels in the previous tests for the polythene and rubber articles. They show a steady decline over the sevenday period of aeration but the levels then obtained are still many times larger than those found after formaldehyde sterilization even when this is estimated immediately after exposure. Levels in cotton, wool, and paper are more comparable but ethylene oxide levels are still higher.

These methods of exposure and subsequent aqueous extraction cannot of course be said to measure the total content of formaldehyde or ethylene oxide in the article concerned. They were adopted as giving a reasonable approximation to the situation in vivo when the agent absorbed into the substance of the article might be extracted into an ambient aqueous solution either in the patient himself or by some solution passing through the article and into the patient's body. Preliminary estimations showed that in fact the greater proportion of formaldehyde or ethylene oxide released from the article into the water is during the first few hours of extraction and that no significant quantity is released after 24 hours.

One cannot, except by methods such as steam 
TABLE III

ETHYLENE OXIDE ESTIMATION (EXPRESSED AS HCHO PPM)

$\mathrm{HCHO}$ (ppm) in Article

\begin{tabular}{|c|c|c|c|c|c|c|}
\hline \multirow[b]{2}{*}{ Article } & \\
\hline & Day 0 & Day 1 & Day 2 & Day 3 & Day 7 & Control \\
\hline \multirow{7}{*}{$\begin{array}{l}\text { Rubber tube large bore } \\
\text { Rubber tube small bore } \\
\text { Polythene tube } \\
\text { large bore } \\
\text { Polythene tube } \\
\text { small bore } \\
\text { Cotton cloth } \\
\text { Paper } \\
\text { Cotton cellular blanket } \\
\text { Woollen blanket }\end{array}$} & 1770.0 & $530 \cdot 0$ & 216.0 & 91.9 & $47 \cdot 3$ & 4.05 \\
\hline & $1940 \cdot 0$ & $338 \cdot 0$ & $108 \cdot 0$ & $84 \cdot 6$ & $42 \cdot 3$ & 0 \\
\hline & $1670 \cdot 0$ & $861 \cdot 0$ & $3610 \cdot 0$ & $400 \cdot 0$ & $128 \cdot 0$ & 0 \\
\hline & $1800 \cdot 0$ & $700 \cdot 0$ & 230.0 & 75.0 & $75 \cdot 0$ & $16 \cdot 7$ \\
\hline & $3130 \cdot 0$ & 3230.0 & $2730 \cdot 0$ & 3170.0 & $2070 \cdot 0$ & 0 \\
\hline & $7420 \cdot 0$ & $1000 \cdot 0$ & 960.0 & 940.0 & $940 \cdot 0$ & 0 \\
\hline & $7450 \cdot 0$ & $1260 \cdot 0$ & $1300 \cdot 0$ & 1360.0 & 1550.0 & 0 \\
\hline
\end{tabular}

distillation, extract from any article all of these chemicals absorbed into or combined with it. To attempt an assessment of the efficiency of cold water extraction, rubber and polythene articles exposed to formaldehyde or ethylene oxide by the standard methods described were extracted under reflux into $250 \mathrm{ml}$ of boiling water in each case. The amounts of formaldehyde or ethylene oxide released were then determined.

The results showed that soaking overnight in $250 \mathrm{ml}$ of distilled water extracts $92 \%$ of the ethylene oxide from polythene and $75.4 \%$ from rubber and $75 \%$ of formaldehyde from polythene and $34 \%$ from rubber when the reflux extraction is regarded as yielding $100 \%$ in each case.

\section{DISCUSSION}

As long as it is still necessary to sterilize heatlabile materials at hospital level, any decision on the method to be used means taking into account the advantages and disadvantages of ethylene oxide and low-temperature steam and formaldehyde.

It is recognized that a major disadvantage of ethylene oxide is the high residuum of the toxic chemical which remains absorbed into many articles after the sterilization period is over. This has necessitated the acceptance of an 'airing off' period of at least 24 hours before use. We have shown that in fact even this length of time is not sufficient to disperse the ethylene oxide which remains and can be released by aqueous extraction from materials such as rubber and polythene as well as paper and cloth. Similar tests carried out to estimate the residual formaldehyde after exposure to lowtemperature steam and formaldehyde have shown that this is of a significantly lower level and is reduced in most cases even further with aeration. These low formaldehyde residual levels, using the low-temperature steam and formaldehyde process, may be a result of the prevention of polymerization of the chemical on fabric and material by the pre- sence of steam acting as a vehicle for it, and by the maintenance of the temperature at $80^{\circ} \mathrm{C}$ while $y$ pressure is subatmospheric. The powerful postvacuum period must also contribute to the removal 은 of the residual traces of the formaldehyde. The lowtemperature steam and formaldehyde process seems thus to have removed what was regarded as a major disadvantage of formalin sterilization only a few years ago (Kelsey, 1963). Indeed we would suggest that the low residual levels of formaldehyde in rubber and plastic when compared with the relatively high levels of ethylene oxide following the use of that gas could be regarded as a major advantage of the low-temperature steam and formaldehyde process.

The levels of residual formaldehyde following the processing of cotton, paper, and wool are particularly interesting. The occurrence of cases of contact dermatitis resulting apparently from residual formaldehyde in textiles is well established. The levels we obtained in control samples of cotton, paper, and wool were very much lower than those in the processed samples, even after up to seven days' airing off, but the use of formaldehyde amine resins in the manufacture of the materials could not be established. As the figures obtained, for example, by Blohm (1959) in his estimations on various textiles, cannot be compared with ours, further work would have to be done to establish comparisons for levels between residual formaldehyde in 'finished' textiles and residual formaldehyde in material exposed to the steam/formaldehyde process. Alder and Gillespie, however, have used formaldehyde-treated blankets for years with no reports of contact dermatitis (Gillespie and Alder, 1957; Gillespie, Alder, Ayliffe, Bradbeer, and Wypkema, 1959).

The persistent levels of formaldehyde in fabric and paper following the steam/formaldehyde process may of course have advantages. Dickinson and Wagg (1967) have recently shown that a formaldehyde rinse in the laundering of blankets gives them strong self-disinfecting powers. The same effect 
occurs in blankets treated with steam and formaldehyde and then stored (Alder, 1968). The residual levels in paper might be used in the storage of goods from central sterilization departments, for example, to play a similar self-disinfecting role in paper bags and wraps. A small injection of formaldehyde vapour into the chamber during autoclaving might be of value in this respect.

The method used to recover the chemicals by aqueous extraction does, we feel, give meaningful results but we cannot, except by a method such as steam distillation or reflux, claim to have extracted from any article all of such chemicals absorbed into or combined with it. However, the results obtained by aqueous extraction represent a major proportion of the total which could be extracted by refluxing. In any case the level of recovered formaldehyde or ethylene oxide obtained by aqueous extraction may well bear a closer relation to the levels likely to be found in use in vivo when aqueous solutions are passed through tubing into a patient, or the tubing or other article is inserted into a patient and surrounded by aqueous solutions. The solubility of both ethylene oxide and formaldehyde in water is high compared with the levels obtained in the aqueous extractions and enables us to discount this factor in comparisons.

We consider that in rubber and plastic articles, residual levels of formaldehyde following the lowtemperature steam and formaldehyde sterilization process are not likely to be toxic to patients. They are certainly much lower than the ethylene oxide levels we obtained following sterilization by that gas. In fabric and paper the higher formaldehyde levels may in fact be of value as they may give a continuing self-disinfecting effect during storage.

\section{REFERENCES}

Alder, V. G. (1968). Cospar Technical Bulletin (in the press). $\longrightarrow$, Brown, A. M., and Gillespie, W. A. (1966). J. clin. Path., 19, 83. Blohm, S. G. (1959). Acta derm,-venereol. (Stockh.), 39, 450.

Critchfield, E. E., and Johnson, J. B. (1957). Anal. Chem., 29, 797. Dickinson, J. C., and Wagg, R. E. (1967). J. Appl. Bact., 30, 340. Gibson, G. L., Johnston, H. P. (1967). Brit. Hosp. J. and Soc. Sci. Rev., 77, 1208.

Gillespie, W. A., and Alder, V. G. (1957). Lancet, 1, 632.

$\longrightarrow$, - Ayliffe, G. A. J., Bradbeer, J. W., and Wypkema, W. (1959). Ibid., 2, 781.

Kelsey, J. C. (1963). J. clin. Path., 16, 542.

Marcussen, P. V. (1959). Acta derm.-venereol. (Stockh.), 39, 348.

Wereide, K. (1964). Acta allerg. (Kbh), 19, 351.

\section{Reports and Bulletins prepared by the Association of Clinical Biochemists}

The following reports and bulletins are published by the Association of Clinical Biochemists. They may be obtained from The Administrative Office, Association of Clinical Biochemists, 7 Warwick Court, Holborn, London, W.C.1. The prices include postage, but airmail will be charged extra.

\section{SCIENTIFIC REPORTS}

1 Colorimeters with Flow Through Cells. A critical assessment of 4 instruments. 1965. P. M. G. BROUGHTON and C. RILEY. 13s. 6d.

2 Colorimeters. A critical assessment of 5 commercial instruments. 1966. P. M. G. BROUGHTON, C. RILEY, J. G. H. COOK, P. G. SANDERS, and H. BRAUNSBERG. $15 \mathrm{~s}$.

3 Automatic Dispensing Pipettes. An assessment of 35 commercial instruments. 1967. P. M. G. BROUGHTON, A. H. GOWENLOCK, G. M. WIDDOWSON, and K. A. AHLQUIST. 10 s.

TECHNICAL BULLETINS

9 Determination of Urea by AutoAnalyzer. November 1966. RUTH M. HASLAM. 2s. $6 d$.
10 Filter Fluorimeters. A comparative list of 14 instruments. March 1967. HANNELORE BRAUNSBERG. 5s.

11 Determination of Serum Albumin by AutoAnalyzer using Bromocresol Green. October 1967. B. E. NORTHAM and G. M. WIDDOWSON. 2s. 6d.

12 Control Solutions for Clinical Biochemistry. February 1968. P. M. G. BROUGHTON. 2 s. 6 d.

13 An Assessment of the Technicon Type II Sampler Unit. March 1968. B. C. GRAY and G. K. MCGOWAN. 1s. 6d.

14 Atomic Absorption Spectroscopy. An Outline of its Principles and a Guide to the Selection of Instruments. May 1968. J. B. DAWSON and P. M. G. BROUGHTON. 4s.

15 A Guide to Automatic Pipettes (2nd edition). June 1968. P. M. G. BROUGHTON. $5 \mathrm{~s}$. 